Review Article

\title{
Risk of Malignant Neoplasia with Glucagon-Like Peptide-1 Receptor Agonist Treatment in Patients with Type 2 Diabetes: A Meta-Analysis
}

\author{
Yufang Liu $\mathbb{D}^{1},{ }^{1}$ Xiaomei Zhang, ${ }^{1}$ Sanbao Chai, ${ }^{1}$ Xin Zhao, ${ }^{1}$ and Linong Ji $\mathbb{D}^{2}$ \\ ${ }^{1}$ Department of Endocrinology, Peking University International Hospital, Beijing 102206, China \\ ${ }^{2}$ Department of Endocrinology, Peking University People's Hospital, Beijing 100044, China \\ Correspondence should be addressed to Linong Ji; prof_jilinong@aliyun.com
}

Received 19 March 2019; Accepted 2 July 2019; Published 16 July 2019

Academic Editor: Ferdinando Carlo Sasso

Copyright (c) 2019 Yufang Liu et al. This is an open access article distributed under the Creative Commons Attribution License, which permits unrestricted use, distribution, and reproduction in any medium, provided the original work is properly cited.

\begin{abstract}
Background. Glucagon-like peptide-1 (GLP-1) receptor agonists are effective glucose-lowering drugs, but there is concern that they may increase the risk of malignant neoplasia. The present meta-analysis examined the safety of GLP-1 receptor agonists with regard to malignant neoplasia. Methods. We analyzed data from randomized controlled trials with a minimum duration of 24 weeks that assessed the incidence of neoplasms in type 2 diabetes patients receiving GLP-1 receptor agonists compared with placebo or other hypoglycemic drugs. We searched the MEDLINE, Embase, and Cochrane databases with a language restriction of English through October 1, 2018, and carried out a meta-analysis of the available trial data using a fixed effects model to calculate odds ratios (ORs) for neoplasia. Results. Thirty-four relevant articles, providing data for 50452 patients, were included in the meta-analysis. Compared with the incidence of malignant neoplasia with placebo or other interventions, no increase in malignant neoplasm formation was observed with the use of GLP-1 receptor agonists (OR 1.04, 95\% confidence interval (CI) $0.94-1.15 ; p=0.46$ ), liraglutide (OR 1.08, 95\% CI 0.91-1.27; $p=0.38$ ), exenatide (OR 1.00, 95\% CI 0.86-1.16; $p=1.00$ ), semaglutide (OR 0.89, 95\% CI $0.35-2.22$; $p=0.80$ ), or albiglutide (OR 1.07, 95\% CI $0.23-4.88 ; p=0.93$ ). A subanalysis of trials lasting longer than 3 years also showed no increase in the neoplasia risk with GLP-1 receptor agonist use (OR 1.03, 95\% CI 0.92-1.15; $p=0.60$ ). Betweentrial statistical heterogeneity was low for all comparisons. Conclusion. GLP-1 receptor agonists can be used without safety concerns related to malignant neoplasia in patients with type 2 diabetes.
\end{abstract}

\section{Introduction}

Glucagon-like peptide-1 (GLP-1) receptor agonists are a class of hypodermic hypoglycemic drugs that are effective for the treatment of type 2 diabetes mellitus. A number of GLP-1 receptor agonists have already been approved by the Food and Drug Administration (FDA) for type 2 diabetes treatment, including exenatide, liraglutide, semaglutide, lixisenatide, dulaglutide, albiglutide, and others. Based on the findings of several cardiovascular outcome trials (CVOTs) [1], GLP-1 receptor agonists and sodium-glucose cotransporter 2 (SGLT2) inhibitors are highly recommended as types of antidiabetic drugs, second only to metformin. GLP-1 receptor agonists are especially recommended, given that cardiovascular disease is the major cause of death among patients with type 2 diabetes.

However, some studies have indicated that GLP-1 receptor agonists may be associated with an increased risk of malignant neoplasia. In animal models, GLP-1 receptor agonist treatment was linked to an increased risk of pancreatic cancer and thyroid C-cell cancer [2,3]. At the same time, studies conducted in humans found increased risks of acute pancreatitis and pancreatic cancer with the use of GLP-1 receptor agonists [4]. In 2014, a US FDA and European Medical Association (EMA) assessment published in the New England Journal of Medicine stated that a final conclusion could not be made regarding a causal relationship between incretin-based drugs and pancreatitis or pancreatic cancer. 


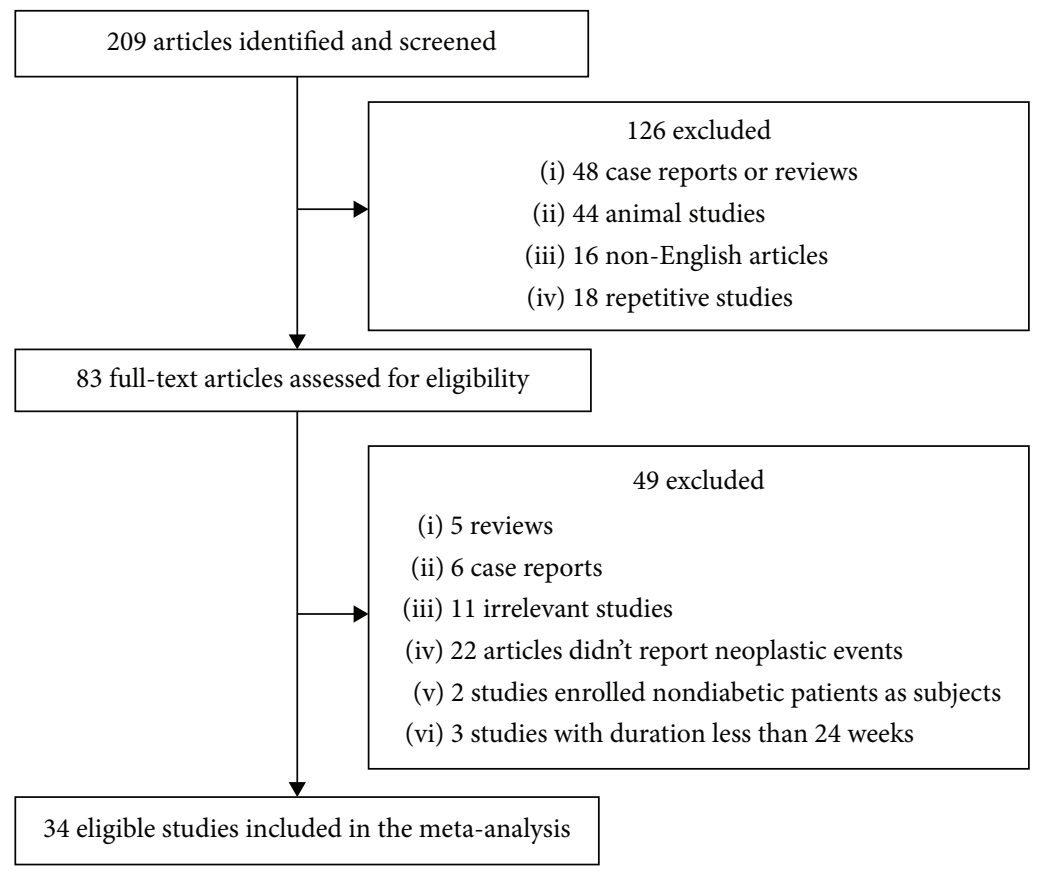

FIgURE 1: Study selection.

Thus, additional meta-analyses and continued investigations into the safety of these drugs are needed [5]. Since then, several reviews have explored the associations between incretin-based drugs and pancreatic cancer [6-10]. Until now though, almost all reviews have focused on pancreatic cancer, and no review studying the association of GLP-1 receptor agonists with all types of malignant neoplasms has been published, despite the availability of data for the incidence of various types of cancer, including breast cancer, prostate cancer, and others, in patients taking GLP-1 receptor agonists. Therefore, the objective of this metaanalysis was to summarize the evidence for an association between GLP-1 receptor agonists and the incidence of all forms of malignant neoplasms.

\section{Methods}

This systematic review was registered in PROSPERO (registration number CRD42019122052).

2.1. Search Strategy and Study Selection Criteria. In this systematic review and meta-analysis, we regarded studies as eligible for the inclusion criteria if they were randomized controlled trials (RCTs) that included adult patients with type 2 diabetes, compared a GLP-1 receptor agonist to another treatment strategy with a minimum treatment duration of 24 weeks, and reported the number of participants who developed neoplasms during follow-up. We retained all potentially eligible studies for review, independent of the primary outcome of each study. We searched the MEDLINE, Embase, and Cochrane databases for eligible trials, with a language restriction of English. The search strategy was based on "subject terms+free terms." Subject terms used in the searches were "glucagon-like peptide-1 receptor agonist," "exenatide," "liraglutide," "semaglutide," "lixisenatide," "dulaglutide," "albiglutide," "neoplasms," and "diabetes mellitus." With regard to neoplasms, we included studies of all types of malignant tumors and excluded those evaluating benign tumor formation. For the search for RCTs, we used available filters to search only for RCTs from the Harvard Library. Searches were done through October 1, 2018.

Two independent investigators reviewed study titles and abstracts, and studies that satisfied the inclusion criteria were assessed by screening of the full text. Trials selected for detailed analysis and data extraction were analyzed by two investigators, and disagreements were resolved by a third investigator. For quality assessment, Cochrane Collaboration's Tool for Assessing Risk of Bias in RCTs was used.

2.2. Statistical Analysis. When specific data were not available, requests for the information were sent to the corresponding authors of the trial articles. We calculated ORs and $95 \%$ confidence intervals (CIs) for the numbers of neoplasia events by the treatment group. We used a fixed effects model meta-analysis if the between-trial statistical heterogeneity was low. We used a random effects model meta-analysis if the between-trial statistical heterogeneity was high. The possibility of publication bias was assessed by constructing a funnel plot of each trial's effect size against the standard error. The heterogeneity of treatment effects between trials was assessed by the $I^{2}$ index and Cochran's $Q$ test, with $p$ values $<0.05$ on Cochran's $Q$ test representing significant heterogeneity. The $I^{2}$ index thresholds describing the degree of heterogeneity were $25 \%$ or lower (low), $26-50 \%$ (moderate), and greater than 50\% (high). RevMan (version 5.1) software was used for all statistical analyses. 
TABLE 1: Trial design features and results.

\begin{tabular}{|c|c|c|c|c|c|c|c|c|}
\hline \multirow[b]{2}{*}{ Author/year } & \multirow[b]{2}{*}{ Trial/program } & \multicolumn{2}{|c|}{ Interventions } & \multirow{2}{*}{$\begin{array}{c}\text { Trial } \\
\text { duration } \\
\text { (weeks) }\end{array}$} & \multicolumn{2}{|c|}{ Experimental } & \multicolumn{2}{|l|}{ Control } \\
\hline & & Experimental & Control & & $\begin{array}{c}\text { Number of } \\
\text { events }\end{array}$ & $N$ & $\begin{array}{c}\text { Number of } \\
\text { events }\end{array}$ & $N$ \\
\hline Gallwitz et al. 2012 [11] & EUREXA & Exenatide & Glimepiride & 102 & 3 & 515 & 1 & 514 \\
\hline Russel-Jones et al. 2012 [12] & DURATION-4 & Exenatide & Metformin & 26 & 0 & 248 & 1 & 246 \\
\hline Kadowaki et al. 2010 [13] & & Exenatide & Placebo & 24 & 1 & 144 & 0 & 35 \\
\hline Xu et al. 2014 [14] & CONFIDENCE & Exenatide & $\begin{array}{l}\text { Premixed } \\
\text { insulin }\end{array}$ & 48 & 1 & 110 & 0 & 114 \\
\hline Jaiswal et al. 2015 [15] & & Exenatide & Glargine & 77 & 1 & 22 & 0 & 24 \\
\hline Diamant et al. 2014 [16] & DURATION-3 & Exenatide & Glargine & 156 & 3 & 140 & 2 & 147 \\
\hline Diamant et al. 2012 [17] & & Exenatide & Glargine & 84 & 2 & 173 & 1 & 173 \\
\hline Bergenstal et al. 2010 [18] & DURATION-2 & Exenatide & Sitagliptin & 26 & 0 & 160 & 1 & 166 \\
\hline Holman et al. 2017 [19] & EXSCEL & Exenatide & Placebo & 167 & 355 & 7356 & 361 & 7396 \\
\hline Gadde et al. 2017 [20] & DURATION-NEO-2 & Exenatide & Placebo & 28 & 0 & 181 & 0 & 61 \\
\hline Weinstock et al. 2015 [21] & AWARD-5 & Dulaglutide & Sitagliptin & 26 & 8 & 606 & 5 & 315 \\
\hline Araki et al. 2015 [22] & & Dulaglutide & Glargine & 26 & 0 & 181 & 0 & 180 \\
\hline Blonde et al. 2015 [23] & AWARD-4 & Dulaglutide & Glargine & 52 & 0 & 588 & 0 & 296 \\
\hline Umpierrez et al. 2014 [24] & AWARD-3 & Dulaglutide & Metformin & 52 & 0 & 539 & 0 & 268 \\
\hline Pozzilli et al. 2017 [25] & AWARD-9 & Dulaglutide & Glargine & 28 & 0 & 150 & 1 & 150 \\
\hline Miyagawa et al. 2015 [26] & & $\begin{array}{l}\text { Dulaglutide } \\
\text { Liraglutide }\end{array}$ & Placebo & 52 & $\begin{array}{l}0 \\
1\end{array}$ & $\begin{array}{l}281 \\
141\end{array}$ & 0 & 70 \\
\hline Bailey et al. 2016 [27] & LIRA-SWITCH & Liraglutide & Sitagliptin & 26 & 0 & 202 & 2 & 204 \\
\hline Zang et al. 2016 [28] & & Liraglutide & Sitagliptin & 26 & 0 & 183 & 2 & 184 \\
\hline Marso et al. 2016 (Liraglutide) [1] & LEADER & Liraglutide & Placebo & 198 & 296 & 4668 & 279 & 4672 \\
\hline Pratley et al. 2011 [29] & & Liraglutide & Sitagliptin & 52 & 4 & 446 & 1 & 219 \\
\hline le et al. 2017 [30] & SCALE & Liraglutide & Placebo & 160 & 11 & 1501 & 1 & 747 \\
\hline Marso et al. 2016 (Semaglutide) [31] & SUSTAIN-6 & Semaglutide & Placebo & 104 & 1 & 1648 & 4 & 1649 \\
\hline Ahrén et al. 2017 [32] & SUSTAIN 2 & Semaglutide & Sitagliptin & 52 & 2 & 818 & 2 & 407 \\
\hline Sorli et al. 2017 [33] & SUSTAIN 1 & Semaglutide & Placebo & 30 & 4 & 258 & 0 & 129 \\
\hline Davies et al. 2017 [34] & & Semaglutide & Placebo & 26 & 1 & 419 & 0 & 71 \\
\hline Aroda et al. 2017 [35] & SUSTAIN 4 & Semaglutide & Glargine & 30 & 4 & 722 & 1 & 360 \\
\hline Reusch et al. 2014 [36] & HARMONY 1 & Albiglutide & Placebo & 52 & 0 & 150 & 0 & 151 \\
\hline Home et al. 2015 [37] & HARMONY 5 & Albiglutide & Placebo & 156 & 0 & 271 & 1 & 115 \\
\hline Weissman et al. 2014 [38] & HARMONY 4 & Albiglutide & Glargine & 52 & 0 & 504 & 0 & 241 \\
\hline Nauck et al. 2015 [39] & HARMONY 2 & Albiglutide & Placebo & 52 & 2 & 204 & 0 & 105 \\
\hline Leiter et al. 2014 [40] & & Albiglutide & Sitagliptin & 52 & 0 & 249 & 0 & 246 \\
\hline Leiter et al. 2017 [41] & & Albiglutide & Lispro & 52 & 1 & 285 & 0 & 281 \\
\hline Yu et al. 2014 [42] & GetGoal-M-Asia & Lixisenatide & Placebo & 24 & 0 & 196 & 0 & 194 \\
\hline Pfeffer et al. 2015 [43] & ELIXA & Lixisenatide & Placebo & 108 & 72 & 3031 & 61 & 3032 \\
\hline
\end{tabular}

\section{Results}

3.1. Study Selection. Our database searches identified 209 studies, of which 34 (presenting data for 50452 participants) were included in our analysis (Figure 1). Among the initial 209 trials, 126 were excluded for being a case report, review, animal study, non-English article, or repetitive study based on reading of the title and abstract. For the remaining 83 articles, two authors separately read the full-text articles in detail to assess their eligibility, and 49 trials were further excluded (5 reviews, 6 case reports, 11 irrelevant studies, 22 not reporting neoplastic events, 2 with nondiabetic subjects, and 3 with a duration less than 24 weeks). The 34 trials included in the final analyses were all published between 2010 and 2017 (Table 1). The trial duration ranges from 24 to 198 weeks, and all trials excluded patients with a history of neoplasms at baseline.

Fourteen trials compared treatment outcomes achieved with GLP-1 receptor agonists versus placebo with or without oral antidiabetic drugs. The other 20 included trials compared outcomes achieved with GLP-1 receptor agonists to those obtained with metformin (2 trials), sitagliptin (7 trials), glimepiride (1 trial), premixed insulin ( 1 trial), glargine ( 8 trials), or lispro (1 trial). Many types of neoplasms occurred in 


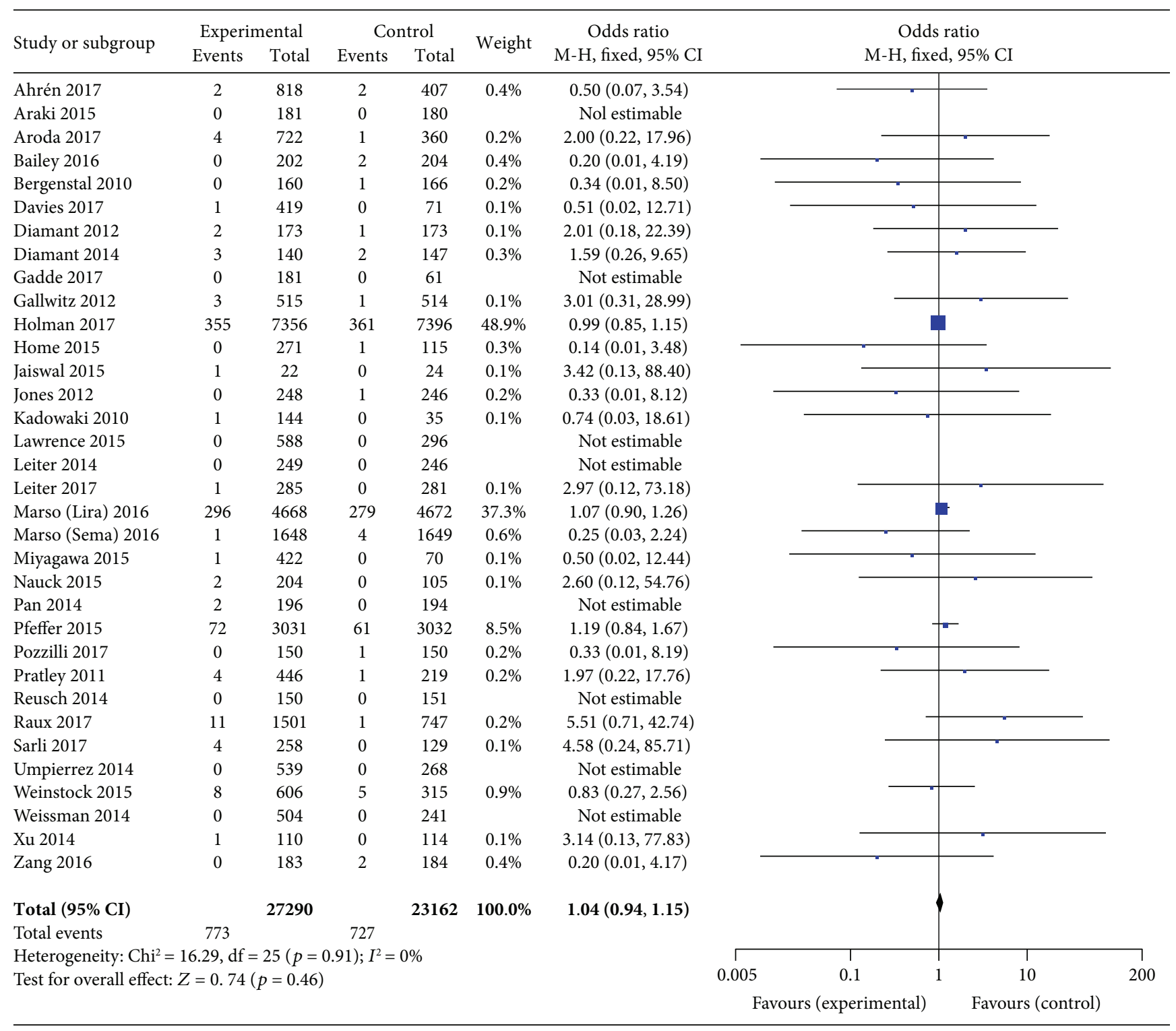

FIGURE 2: Meta-analysis of the incidence of neoplasms with the use of all tested GLP-1 receptor agonists versus placebo or other antidiabetic treatments.

these trials, including pancreatic cancer, thyroid cancer, breast cancer, gastrointestinal cancer, skin cancer, leukemia, lymphoma, prostate cancer, and others. For trials belonging to the same program, such as the DURATION-2, DURATION-3, and DURATION-4 studies, detailed assessment was performed to exclude duplicate data.

3.2. Incidence of Neoplasia with All GLP-1 Receptor Agonists. Compared with placebo or other interventions, GLP-1 receptor agonist use showed no association with an increased risk of neoplasm development (OR 1.04, 95\% CI 0.94-1.15; $p=$ $0.46)$, with no statistically significant between-study heterogeneity $\left(I^{2}=0 \%, p=0.91\right.$; Figure 2$)$. Eight trials were not included in this analysis, because no neoplasms were reported among their patients. The funnel plot for this analysis indicated no significant publication bias (Figure 3 ).
3.3. Subgroup Analyses of the Incidence of Neoplasia with Different GLP-1 Receptor Agonists. Among all 34 included trials, 6 trials (with data for 13237 patients) employed liraglutide as the experimental agent. Compared with placebo or other interventions, liraglutide use was not associated with an increased incidence of neoplasms (OR 1.08, 95\% CI $0.91-1.27 ; p=0.38)$, and no statistically significant between-study heterogeneity was observed $\left(I^{2}=3 \%, p=\right.$ 0.40; Figure 4).

Among all 34 included trials, 10 trials (with data for 17925 patients) employed exenatide as the experimental agent. Compared with placebo or other interventions, exenatide use was not associated with an increased incidence of neoplasia (OR 1.00, 95\% CI $0.86-1.16 ; p=1.00$ ), and no statistically significant between-study heterogeneity was observed $\left(I^{2}=0 \%, p=0.90\right.$; Figure 4$)$. One trial that used 


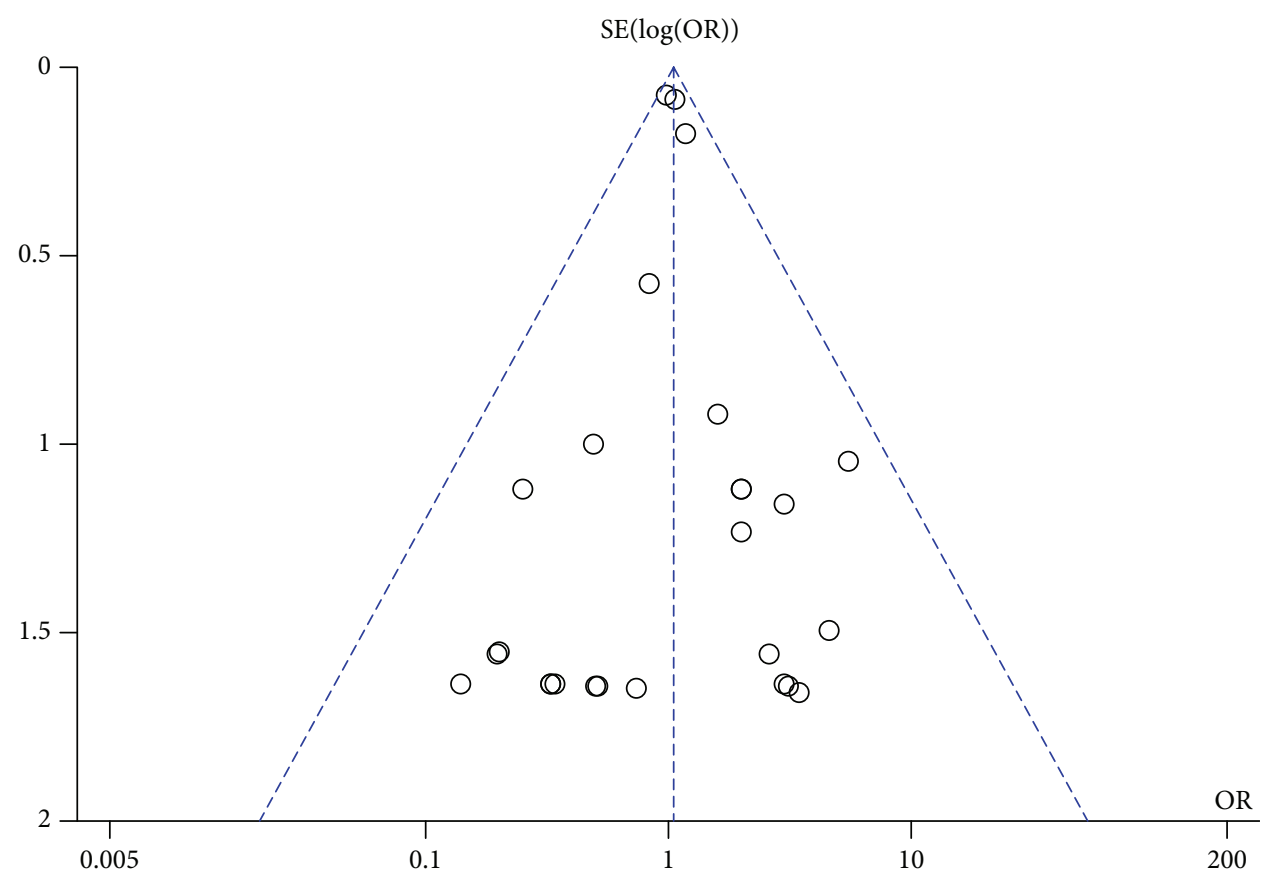

FIGURE 3: Funnel plot for the comparison of the incidence of neoplasia with the use of GLP-1 receptor agonists versus placebo or other antidiabetic treatments.

exenatide was excluded from the meta-analysis, because it did not report any neoplasia events.

Among the 34 included trials, 5 trials (with data for 6481 patients) employed semaglutide as the experimental agent. Compared with placebo or other interventions, semaglutide use was not associated with an increase in neoplasm formation (OR 0.89, 95\% CI 0.35-2.22; $p=0.80$ ), and no statistically significant between-study heterogeneity was observed $\left(I^{2}=0 \%, p=0.48\right.$; Figure 4$)$.

Among the 34 included trials, 6 trials (with data for 2802 patients) employed albiglutide as the experimental agent. Compared with placebo or other interventions, albiglutide use was not associated with an increased incidence of neoplasia (OR 1.07, 95\% CI 0.23-4.88; $p=0.93$ ), and no statistically significant between-study heterogeneity was observed $\left(I^{2}=11 \%, p=0.32\right.$; Figure 4). Data from three trials were not included in this comparison, because they did not report any neoplasia events.

3.4. Incidence of Neoplasia with GLP-1 Receptor Agonists versus Placebo. Among the 34 included trials, 14 trials (with data for 38876 patients) chose placebo as the only control treatment. Compared with placebo only, GLP-1 receptor agonist use was not associated with an increased incidence of neoplasia (OR 1.04, 95\% CI 0.94-1.16; $p=0.46$ ), and no statistically significant between-study heterogeneity was observed $\left(I^{2}=0 \%, p=0.58\right.$; Figure 5). Data from three trials were not included in this comparison, because they did not report any neoplasia events.

3.5. Subanalysis including Only Trials Lasting at Least 3 Years. Among the 34 included trials, 5 trials (with data for 1309 patients) had a study duration of at least 3 years. The subanalysis of only these 5 trials showed that, compared with placebo or other antidiabetic treatments, GLP-1 receptor agonist use was not associated with an increased incidence of neoplasia (OR 1.03, 95\% CI 0.92-1.15; $p=0.60$ ), and no statistically significant between-study heterogeneity was observed $\left(I^{2}=15 \%, p=0.32\right.$; Figure 6$)$.

\section{Discussion}

Previous studies have reported that GLP-1 receptor agonist use correlated with an increased risk of pancreatic cancer $[4,44]$. Although consistent preclinical, pharmacovigilance, and epidemiologic evidence is lacking, considerable attention has been paid to the potential association between GLP-1 receptor agonists and pancreatic cancer [45-47]. Based on the results of animal studies [2, 44], researchers have speculated that chronic overstimulation of GLP-1 receptors in pancreatic cells could induce pancreatitis, ultimately leading to an increased risk of pancreatic cancer. This speculation has been supported by pharmacovigilance reports [4, 48], and animal studies have also suggested a higher incidence of thyroid C-cell adenomas and carcinomas with once-weekly exenatide than with placebo. Specifically, higher rates of thyroid C-cell tumors and hyperplasia were observed in rodents treated with liraglutide than in control animals [3]. However, these findings have not been replicated in humans.

GLP-1 receptor agonists promote cell proliferation and survival by activating signaling pathways in human islet cells, such as those involving phosphate idylinositol 3 kinase (PI3K) and extracellular regulated kinases 1 and 2 (ERK1/2), which are also frequently activated in human colon cancer cells. ERK1 and ERK2 act on transcription factors such as 


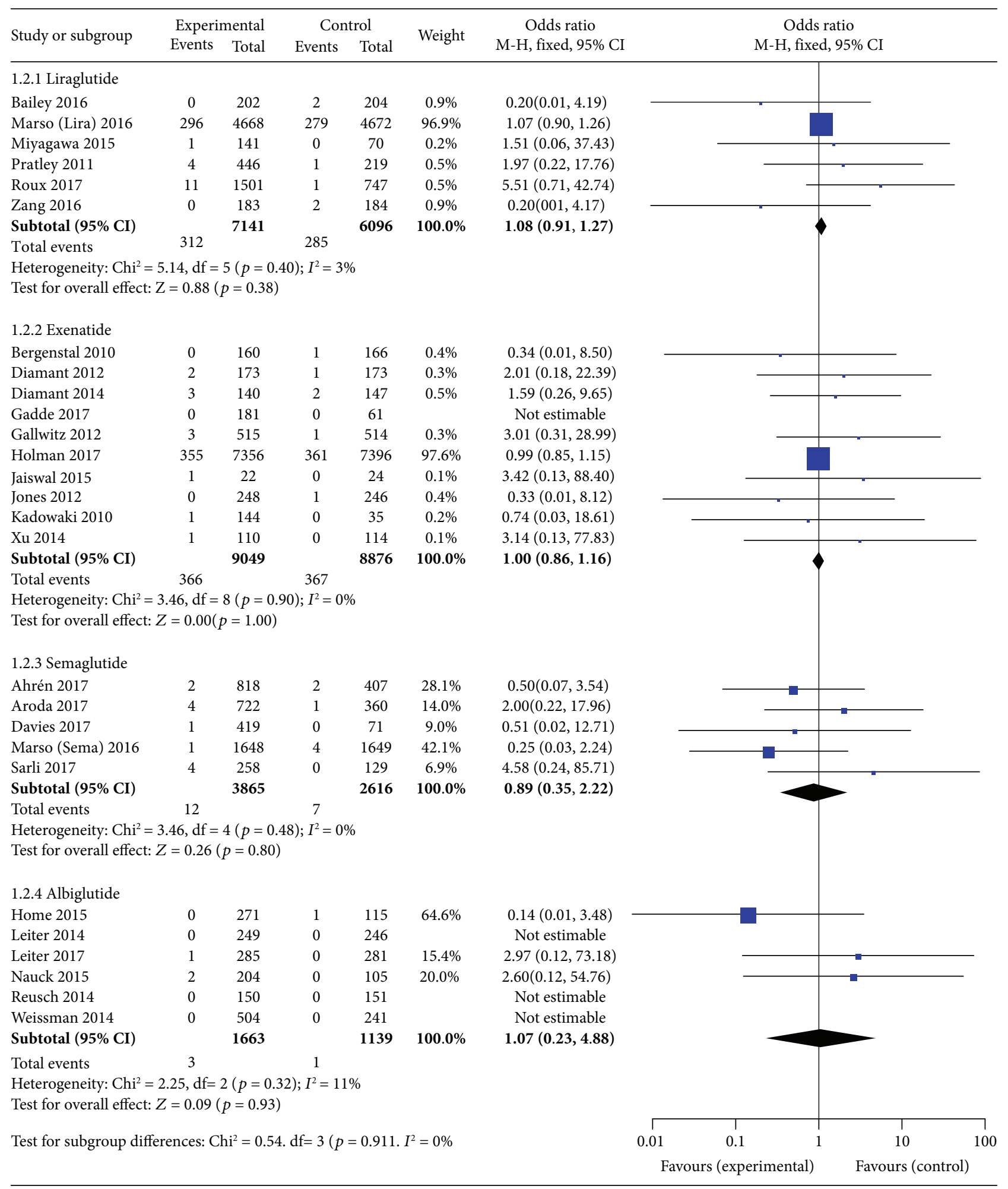

FIgURE 4: Meta-analysis of the incidence of neoplasms with the use of specific GLP-1 receptor agonists versus placebo or other antidiabetic treatments.

E1k-1, c-myc, c-fos, c-jun, activating transcription factor (ATF), nuclear factor- (NF-) $\mathrm{kB}$, and activator protein(AP-) 1, to promote the expression of genes closely related to cell proliferation and differentiation [49]. Thus, it is possi- ble that GLP-1 receptor agonists promote the proliferation of cancer cells, and with the important clinical implications of such an effect, it is necessary to clarify the effects of GLP-1 receptor agonists on cancer cells. 


\begin{tabular}{|c|c|c|c|c|c|c|c|c|c|c|c|}
\hline \multirow{3}{*}{$\begin{array}{l}\text { Study or subgroup } \\
\text { Davies } 2017\end{array}$} & \multicolumn{2}{|c|}{ Experimental } & \multicolumn{2}{|c|}{ Control } & \multirow{3}{*}{$\begin{array}{c}\text { Weight } \\
0.1 \%\end{array}$} & \multirow{3}{*}{$\begin{array}{c}\text { Odds ratio } \\
\text { M-H, fixed, 95\% CI } \\
0.51(0.02,12.71)\end{array}$} & \multirow{2}{*}{\multicolumn{5}{|c|}{$\begin{array}{c}\text { Odds ratio } \\
\text { M-H, fixed, } 95 \% \text { CI }\end{array}$}} \\
\hline & \multirow{2}{*}{$\begin{array}{c}\text { Events } \\
1\end{array}$} & \multirow{2}{*}{$\begin{array}{c}\text { Total } \\
419\end{array}$} & \multirow{2}{*}{$\begin{array}{c}\text { Events } \\
0\end{array}$} & \multirow{2}{*}{$\begin{array}{c}\text { Total } \\
71\end{array}$} & & & & & & & \\
\hline & & & & & & & & & & & \\
\hline Gadde 2017 & 0 & 181 & 0 & 61 & & Not esimable & & & & & \\
\hline Holman 2017 & 355 & 7356 & 361 & 7396 & $50.8 \%$ & $0.99(0.84,1.15)$ & & & I & & \\
\hline Home 2015 & 0 & 271 & 1 & 115 & $0.3 \%$ & $0.14(0.01,3.48)$ & & & & & \\
\hline Kadowaki 2010 & 1 & 144 & 0 & 35 & $0.1 \%$ & $0.74(0.03,17.61)$ & & & & & \\
\hline Marso (Lira) 2016 & 296 & 4668 & 279 & 4672 & $38.7 \%$ & $1.07(0.90,1.26)$ & & & 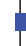 & & \\
\hline Marso (Sema) 2016 & 1 & 1648 & 4 & 1649 & $0.6 \%$ & $0.25(0.03,2.24)$ & & & & & \\
\hline Miyagawa 2015 & 1 & 422 & 0 & 70 & $0.1 \%$ & $0.50(0.02,12.44)$ & & & & & \\
\hline Nauck 2015 & 2 & 204 & 0 & 105 & $0.1 \%$ & $2.60(0.12,51.76)$ & & & & & \\
\hline Pan 2014 & 0 & 196 & 0 & 194 & & Not estimable & & & & & \\
\hline Pfeffer 2015 & 72 & 3031 & 61 & 3032 & $8.8 \%$ & $1.19(0.84,1.67)$ & & & & & \\
\hline Reusch 2014 & 0 & 150 & 0 & 151 & & Not estimable & & & & & \\
\hline Roux 2017 & 11 & 1501 & 1 & 747 & $0.2 \%$ & $5.51(0.71,42.74)$ & & & & & \\
\hline Sorli 2017 & 4 & 258 & 0 & 129 & $0.1 \%$ & $4.58(0.24,85.71)$ & & & & & \\
\hline Total $(95 \% \mathrm{CI})$ & & 20449 & & 18427 & $100.0 \%$ & $1.04(0.94,1.16)$ & & & & & \\
\hline Total events & 744 & & 707 & & & & & & & & \\
\hline \multicolumn{7}{|c|}{ Heterogeneity: $\mathrm{Chi}^{2}=8.51, \mathrm{df}=10(p=0.58) ; I^{2}=0 \%$} & 0.005 & 0.1 & 1 & 10 & 200 \\
\hline \multicolumn{7}{|c|}{ Test for overall effect: $Z=0.75(p=0.46)$} & & expe & & Favours & \\
\hline
\end{tabular}

FIGURE 5: Meta-analysis of the incidence of neoplasia with placebo versus GLP-1 receptor agonists used.

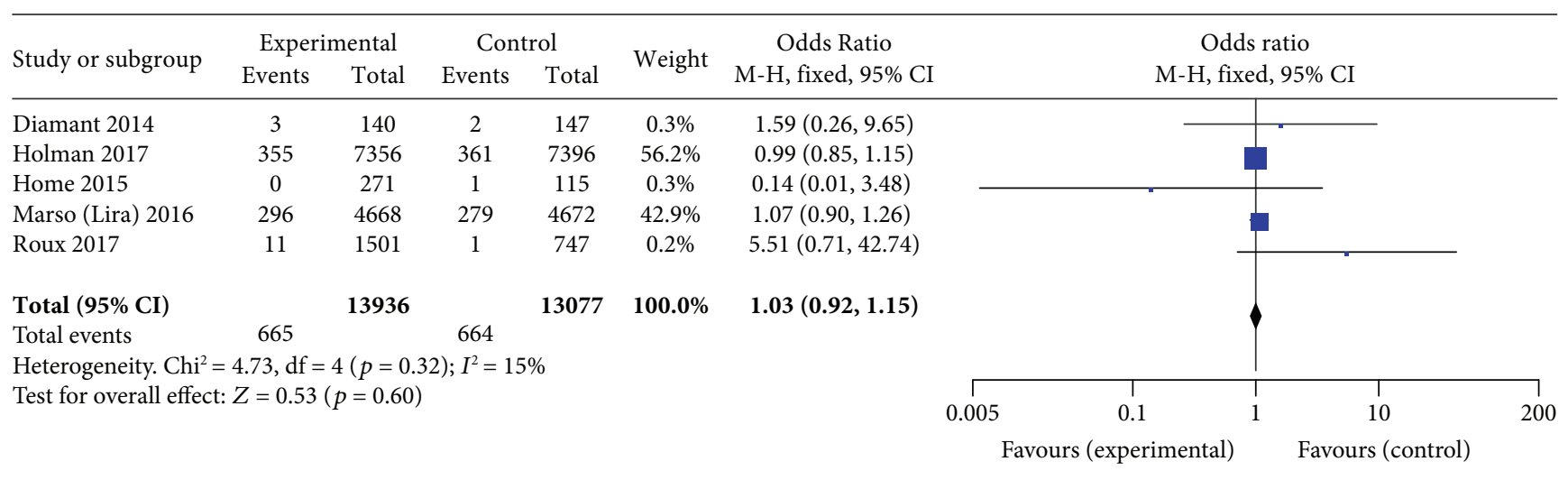

Figure 6: Meta-analysis of the incidence of neoplasia with the use of a GLP-1 receptor agonist versus placebo or other antidiabetic treatments, based on studies with a minimum duration of 3 years.

Research about dipeptidyl peptidase-4 (DPP-4) inhibitors, which function via a similar mechanism as GLP-1 receptor agonists, failed to verify an association between the use of these drugs and an increased risk of site-specific cancer, and this was attributed to the small number of studies for each cancer type and their relatively short duration [50]. Another meta-analysis published in 2017 that included four large-scale studies indicated that GLP-1 receptor agonists did not increase the risk of pancreatic cancer [51], and our study further demonstrated that GLP-1 receptor agonist therapy was not associated with an increased risk of any of the malignant neoplasms studied. This result was true for GLP-1 receptor agonists overall as well as for the specific GLP-1 receptor agonists exenatide, liraglutide, semaglutide, dulaglutide, and albiglutide. Because only two trials used lixisenatide as the experimental intervention, we did not analyze the data for this drug separately, and this was also the case for dulaglutide. Because the between-trial statistical heterogeneity was low for all comparisons, sensitivity analysis was not conducted.

The main strength of this review is that all of the included studies were RCTs. Among all included trials, two RCTs contributed considerable weight to the pooled analysis $[1,19]$. All of the included trials reported consistent results regarding the risk of neoplasms with GLP-1 receptor agonist use, and the meta-analysis strengthened the overall conclusion through the analysis of a much larger sample.

We excluded studies with an intervention duration less than 24 weeks to prevent detection bias or even reverse causality. According to the incidence rates of malignant tumors in humans [52], it is not likely that cancer diagnosed within 24 weeks after initiation of GLP-1 receptor agonist intervention is causally related to the experimental agent. Further analysis of trials with a duration of at least 3 years was 
conducted, as any increase in the incidence of neoplasms due to GLP-1 receptor agonist stimulation should be more readily detected in these trials.

A limitation of the present meta-analysis was the lack of trials with long-term duration, given that neoplasm formation may occur over an extended period. Additionally, patients included in RCTs are generally healthier than realworld patients and are therefore less likely to develop neoplasms than the general patient population or patients in observational studies of new drugs. Moreover, as the occurrence of neoplasia was not the primary or secondary outcome in these RCTs, reporting bias is possible. Although most of the included studies were published in high-impact journals, potential risks of bias such as an open-label design and funding from pharmaceutical companies are still possible, as outlined in the supplementary tables (supplementary material (available here)). Another limitation is that we could not make stratified comparisons according to the different types of neoplasm due to the paucity of original data. Finally, while we excluded studies with a duration less than 24 weeks, most studies did not report the time of neoplasm diagnosis after study enrollment. As a result, some patients likely were diagnosed with a neoplasm after receiving GLP1 receptor agonist intervention for less than 24 weeks but could not be excluded.

\section{Conclusion}

GLP-1 receptor agonists can be used without safety concerns related to the risk of malignant neoplasia in patients with type 2 diabetes.

\section{Conflicts of Interest}

All authors have no conflicts of interest.

\section{Authors' Contributions}

All authors read the manuscript, contributed to its revision, and approved the final submitted version. Yufang Liu and Xiaomei Zhang contributed equally to this work.

\section{Supplementary Materials}

The risk of bias graph review of authors' judgements about each risk of bias item presented as percentages across all included studies. (Supplementary Materials)

\section{References}

[1] S. P. Marso, G. H. Daniels, K. Brown-Frandsen et al., "Liraglutide and cardiovascular outcomes in type 2 diabetes," The New England Journal of Medicine, vol. 375, no. 4, pp. 311-322, 2016.

[2] B. Gier, A. V. Matveyenko, D. Kirakossian, D. Dawson, S. M. Dry, and P. C. Butler, "Chronic GLP-1 receptor activation by exendin-4 induces expansion of pancreatic duct glands in rats and accelerates formation of dysplastic lesions and chronic pancreatitis in the Kras ${ }^{\text {G12D }}$ mouse model," Diabetes, vol. 61, no. 5, pp. 1250-1262, 2012.
[3] L. Bjerre Knudsen, L. W. Madsen, S. Andersen et al., "Glucagon-like peptide-1 receptor agonists activate rodent thyroid C-cells causing calcitonin release and C-cell proliferation," Endocrinology, vol. 151, no. 4, pp. 1473-1486, 2010.

[4] M. Elashoff, A. V. Matveyenko, B. Gier, R. Elashoff, and P. C. Butler, "Pancreatitis, pancreatic, and thyroid cancer with glucagon-like peptide-1-based therapies," Gastroenterology, vol. 141, no. 1, pp. 150-156, 2011.

[5] A. G. Egan, E. Blind, K. Dunder et al., "Pancreatic safety of incretin-based drugs-FDA and EMA assessment," The New England Journal of Medicine, vol. 370, no. 9, pp. 794-797, 2014.

[6] C. Alves, F. Batel-Marques, and A. F. Macedo, "A metaanalysis of serious adverse events reported with exenatide and liraglutide: acute pancreatitis and cancer," Diabetes Research and Clinical Practice, vol. 98, no. 2, pp. 271-284, 2012.

[7] H. Chen, X. Zhou, T. Chen et al., "Incretin-based therapy and risk of pancreatic cancer in patients with type 2 diabetes mellitus: a meta-analysis of randomized controlled trials," Diabetes Therapy, vol. 7, no. 4, pp. 725-742, 2016.

[8] J. de Heer and B. Göke, "Are incretin mimetics and enhancers linked to pancreatitis and malignant transformations in pancreas," Expert Opinion on Drug Safety, vol. 13, no. 11, pp. 1469-1481, 2014.

[9] E. A. Suarez, C. E. Koro, J. B. Christian, A. D. Spector, A. B. Araujo, and S. Abraham, "Incretin-mimetic therapies and pancreatic disease: a review of observational data," Current Medical Research and Opinion, vol. 30, no. 12, pp. 24712481, 2014.

[10] H. Wang, Y. Liu, Q. Tian et al., "Incretin-based therapies and risk of pancreatic cancer in patients with type 2 diabetes: a meta-analysis of randomized controlled trials," Diabetes, Obesity \& Metabolism, vol. 20, no. 4, pp. 910-920, 2018.

[11] B. Gallwitz, J. Guzman, F. Dotta et al., "Exenatide twice daily versus glimepiride for prevention of glycaemic deterioration in patients with type 2 diabetes with metformin failure (EUREXA): an open-label, randomised controlled trial," The Lancet, vol. 379, no. 9833, pp. 2270-2278, 2012.

[12] D. Russell-Jones, R. M. Cuddihy, M. Hanefeld et al., "Efficacy and safety of exenatide once weekly versus metformin, pioglitazone, and sitagliptin used as monotherapy in drug-naive patients with type 2 diabetes (DURATION-4): a 26-week double-blind study," Diabetes Care, vol. 35, no. 2, pp. 252258, 2012.

[13] T. Kadowaki, M. Namba, T. Imaoka et al., "Improved glycemic control and reduced bodyweight with exenatide: a doubleblind, randomized, phase 3 study in Japanese patients with suboptimally controlled type 2 diabetes over 24 weeks," Journal of Diabetes Investigation, vol. 2, no. 3, pp. 210-217, 2011.

[14] W. Xu, Y. Bi, Z. Sun et al., "Comparison of the effects on glycaemic control and $\beta$-cell function in newly diagnosed type 2 diabetes patients of treatment with exenatide, insulin or pioglitazone: a multicentre randomized parallel-group trial (the CONFIDENCE study)," Journal of Internal Medicine, vol. 277, no. 1, pp. 137-150, 2015.

[15] M. Jaiswal, C. L. Martin, M. B. Brown et al., "Effects of exenatide on measures of diabetic neuropathy in subjects with type 2 diabetes: results from an 18-month proof-of-concept open-label randomized study," Journal of Diabetes and its Complications, vol. 29, no. 8, pp. 1287-1294, 2015. 
[16] M. Diamant, L. van Gaal, B. Guerci et al., "Exenatide once weekly versus insulin glargine for type 2 diabetes (DURATION-3): 3-year results of an open-label randomised trial," The Lancet Diabetes \& Endocrinology, vol. 2, no. 6, pp. 464473, 2014.

[17] M. Diamant, L. van Gaal, S. Stranks et al., "Safety and efficacy of once-weekly exenatide compared with insulin glargine titrated to target in patients with type 2 diabetes over 84 weeks," Diabetes Care, vol. 35, no. 4, pp. 683-689, 2012.

[18] R. M. Bergenstal, C. Wysham, L. MacConell et al., "Efficacy and safety of exenatide once weekly versus sitagliptin or pioglitazone as an adjunct to metformin for treatment of type 2 diabetes (DURATION-2): a randomised trial," The Lancet, vol. 376, no. 9739, pp. 431-439, 2010.

[19] R. R. Holman, M. A. Bethel, R. J. Mentz et al., "Effects of onceweekly exenatide on cardiovascular outcomes in type 2 diabetes," The New England Journal of Medicine, vol. 377, no. 13, pp. 1228-1239, 2017.

[20] K. M. Gadde, M. L. Vetter, N. Iqbal, E. Hardy, P. Öhman, and on behalf of the DURATION-NEO-2 study investigators, "Efficacy and safety of autoinjected exenatide once-weekly suspension versus sitagliptin or placebo with metformin in patients with type 2 diabetes: the DURATION-NEO-2 randomized clinical study," Diabetes, Obesity and Metabolism, vol. 19, no. 7, pp. 979-988, 2017.

[21] R. S. Weinstock, B. Guerci, G. Umpierrez, M. A. Nauck, Z. Skrivanek, and Z. Milicevic, "Safety and efficacy of once-weekly dulaglutide versus sitagliptin after 2 years in metformin-treated patients with type 2 diabetes (AWARD-5): a randomized, phase III study," Diabetes, Obesity \& Metabolism, vol. 17, no. 9, pp. 849-858, 2015.

[22] E. Araki, N. Inagaki, Y. Tanizawa, T. Oura, M. Takeuchi, and T. Imaoka, "Efficacy and safety of once-weekly dulaglutide in combination with sulphonylurea and/or biguanide compared with once-daily insulin glargine in Japanese patients with type 2 diabetes: a randomized, open-label, phase III, non-inferiority study," Diabetes, Obesity \& Metabolism, vol. 17, no. 10, pp. 994-1002, 2015.

[23] L. Blonde, J. Jendle, J. Gross et al., "Once-weekly dulaglutide versus bedtime insulin glargine, both in combination with prandial insulin lispro, in patients with type 2 diabetes (AWARD-4): a randomised, open-label, phase 3, noninferiority study," The Lancet, vol. 385, no. 9982, pp. 20572066, 2015.

[24] G. Umpierrez, S. Tofé Povedano, F. Pérez Manghi, L. Shurzinske, and V. Pechtner, "Efficacy and safety of dulaglutide monotherapy versus metformin in type 2 diabetes in a randomized controlled trial (AWARD-3)," Diabetes Care, vol. 37, no. 8, pp. 2168-2176, 2014.

[25] P. Pozzilli, P. Norwood, E. Jódar et al., "Placebo-controlled, randomized trial of the addition of once-weekly glucagonlike peptide-1 receptor agonist dulaglutide to titrated daily insulin glargine in patients with type 2 diabetes (AWARD9)," Diabetes, Obesity \& Metabolism, vol. 19, no. 7, pp. 10241031, 2017.

[26] J. Miyagawa, M. Odawara, T. Takamura, N. Iwamoto, Y. Takita, and T. Imaoka, "Once-weekly glucagon-like peptide-1 receptor agonist dulaglutide is non-inferior to once-daily liraglutide and superior to placebo in Japanese patients with type 2 diabetes: a 26-week randomized phase III study," Diabetes, Obesity \& Metabolism, vol. 17, no. 10, pp. 974-983, 2015.
[27] T. S. Bailey, R. Takács, F. J. Tinahones et al., "Efficacy and safety of switching from sitagliptin to liraglutide in subjects with type 2 diabetes (LIRA-SWITCH): a randomized, double-blind, double-dummy, active-controlled 26-week trial," Diabetes, Obesity \& Metabolism, vol. 18, no. 12, pp. 11911198, 2016.

[28] L. Zang, Y. Liu, J. Geng et al., "Efficacy and safety of liraglutide versus sitagliptin, both in combination with metformin, in Chinese patients with type 2 diabetes: a 26-week, open-label, randomized, active comparator clinical trial," Diabetes, Obesity \& Metabolism, vol. 18, no. 8, pp. 803-811, 2016.

[29] R. Pratley, M. Nauck, T. Bailey et al., "One year of liraglutide treatment offers sustained and more effective glycaemic control and weight reduction compared with sitagliptin, both in combination with metformin, in patients with type 2 diabetes: a randomised, parallel-group, open-label trial," International Journal of Clinical Practice, vol. 65, no. 4, pp. 397-407, 2011.

[30] C. W. Le Roux, A. Astrup, K. Fujioka et al., "3 years of liraglutide versus placebo for type 2 diabetes risk reduction and weight management in individuals with prediabetes: a randomised, double-blind trial," The Lancet, vol. 389, no. 10077, pp. 1399-1409, 2017.

[31] S. P. Marso, S. C. Bain, A. Consoli et al., "Semaglutide and cardiovascular outcomes in patients with type 2 diabetes," The New England Journal of Medicine, vol. 375, no. 19, pp. 18341844, 2016.

[32] B. Ahrén, L. Masmiquel, H. Kumar et al., "Efficacy and safety of once-weekly semaglutide versus once-daily sitagliptin as an add-on to metformin, thiazolidinediones, or both, in patients with type 2 diabetes (SUSTAIN 2): a 56-week, double-blind, phase 3a, randomised trial," The Lancet Diabetes and Endocrinology, vol. 5, no. 5, pp. 341-354, 2017.

[33] C. Sorli, S. I. Harashima, G. M. Tsoukas et al., "Efficacy and safety of once-weekly semaglutide monotherapy versus placebo in patients with type 2 diabetes (SUSTAIN 1): a doubleblind, randomised, placebo-controlled, parallel-group, multinational, multicentre phase $3 \mathrm{a}$ trial," The Lancet Diabetes and Endocrinology, vol. 5, no. 4, pp. 251-260, 2017.

[34] M. Davies, T. R. Pieber, M. L. Hartoft-Nielsen, O. K. H. Hansen, S. Jabbour, and J. Rosenstock, "Effect of oral semaglutide compared with placebo and subcutaneous semaglutide on glycemic control in patients with type 2 diabetes: a randomized clinical trial," JAMA, vol. 318, no. 15, pp. 1460-1470, 2017.

[35] V. R. Aroda, S. C. Bain, B. Cariou et al., "Efficacy and safety of once-weekly semaglutide versus once-daily insulin glargine as add-on to metformin (with or without sulfonylureas) in insulin-naive patients with type 2 diabetes (SUSTAIN 4): a randomised, open-label, parallel-group, multicentre, multinational, phase 3a trial," The Lancet Diabetes \& Endocrinology, vol. 5, no. 5, pp. 355-366, 2017.

[36] J. Reusch, M. W. Stewart, C. M. Perkins et al., "Efficacy and safety of once-weekly glucagon-like peptide 1 receptor agonist albiglutide (HARMONY 1 trial): 52-week primary endpoint results from a randomized, double-blind, placebo-controlled trial in patients with type 2 diabetes mellitus not controlled on pioglitazone, with or without metformin," Diabetes, Obesity and Metabolism, vol. 16, no. 12, pp. 1257-1264, 2014.

[37] P. D. Home, P. Shamanna, M. Stewart et al., "Efficacy and tolerability of albiglutide versus placebo or pioglitazone over 1 year in people with type 2 diabetes currently taking metformin and glimepiride: HARMONY 5," Diabetes, Obesity \& Metabolism, vol. 17, no. 2, pp. 179-187, 2015. 
[38] P. N. Weissman, M. C. Carr, J. Ye et al., "HARMONY 4: randomised clinical trial comparing once-weekly albiglutide and insulin glargine in patients with type 2 diabetes inadequately controlled with metformin with or without sulfonylurea," Diabetologia, vol. 57, no. 12, pp. 2475-2484, 2014.

[39] M. A. Nauck, M. W. Stewart, C. Perkins et al., "Efficacy and safety of once-weekly GLP-1 receptor agonist albiglutide (HARMONY 2): 52 week primary endpoint results from a randomised, placebo-controlled trial in patients with type 2 diabetes mellitus inadequately controlled with diet and exercise," Diabetologia, vol. 59, no. 2, pp. 266-274, 2016.

[40] L. A. Leiter, M. C. Carr, M. Stewart et al., "Efficacy and safety of the once-weekly GLP-1 receptor agonist albiglutide versus sitagliptin in patients with type 2 diabetes and renal impairment: a randomized phase III study," Diabetes Care, vol. 37, no. 10, pp. 2723-2730, 2014.

[41] L. A. Leiter, J. L. Gross, F. Chow, D. Miller, S. Johnson, and B. Ahrén, "Once weekly glucagon-like peptide-1 receptor agonist albiglutide vs. prandial insulin added to basal insulin in patients with type 2 diabetes mellitus: results over 52 weeks," Journal of Diabetes and its Complications, vol. 31, no. 8, pp. 1283-1285, 2017.

[42] C. Yu Pan, P. Han, X. Liu et al., "Lixisenatide treatment improves glycaemic control in Asian patients with type 2 diabetes mellitus inadequately controlled on metformin with or without sulfonylurea: a randomized, double-blind, placebocontrolled, 24-week trial (GetGoal-M-Asia)," Diabetes/Metabolism Research and Reviews, vol. 30, no. 8, pp. 726-735, 2014.

[43] M. A. Pfeffer, B. Claggett, R. Diaz et al., "Lixisenatide in patients with type 2 diabetes and acute coronary syndrome," The New England Journal of Medicine, vol. 373, no. 23, pp. 2247-2257, 2015.

[44] P. C. Butler, M. Elashoff, R. Elashoff, and E. A. M. Gale, "A critical analysis of the clinical use of incretin-based therapies: are the GLP-1 therapies safe?," Diabetes Care, vol. 36, no. 7, pp. 2118-2125, 2013.

[45] T. Chalmer, T. P. Almdal, T. Vilsbøll, and F. K. Knop, "Adverse drug reactions associated with the use of liraglutide in patients with type 2 diabetes - focus on pancreatitis and pancreas cancer," Expert Opinion on Drug Safety, vol. 14, no. 1, pp. 171-180, 2015.

[46] T. M. Jensen, K. Saha, and W. M. Steinberg, "Is there a link between liraglutide and pancreatitis? A post hoc review of pooled and patient-level data from completed liraglutide type 2 diabetes clinical trials," Diabetes Care, vol. 38, no. 6, pp. 1058-1066, 2015.

[47] C. H. Tseng, K. Y. Lee, and F. H. Tseng, "An updated review on cancer risk associated with incretin mimetics and enhancers," Journal of Environmental Science and Health, Part C: Environmental Carcinogenesis \& Ecotoxicology Reviews, vol. 33, no. 1, pp. 67-124, 2015.

[48] J. L. Faillie, L. Azoulay, V. Patenaude, D. Hillaire-Buys, and S. Suissa, "Incretin based drugs and risk of acute pancreatitis in patients with type 2 diabetes: cohort study," $B M J$, vol. 348 , article g2780, 2014.

[49] M. Tresini, A. Lorenzini, L. Frisoni, R. G. Allen, and V. J. Cristofalo, "Lack of Elk-1 phosphorylation and dysregulation of the extracellular regulated kinase signaling pathway in senescent human fibroblast," Experimental Cell Research, vol. 269, no. 2, pp. 287-300, 2001.

[50] J. A. Overbeek, M. Bakker, A. A. W. A. van der Heijden, M. P. P. van Herk-Sukel, R. M. C. Herings, and G. Nijpels, "Risk of dipeptidyl peptidase-4 (DPP-4) inhibitors on site-specific cancer: a systematic review and meta-analysis," Diabetes/Metabolism Research and Reviews, vol. 34, no. 5, article e3004, 2018.

[51] M. A. Bethel, R. A. Patel, P. Merrill et al., "Cardiovascular outcomes with glucagon-like peptide-1 receptor agonists in patients with type 2 diabetes: a meta-analysis," The Lancet Diabetes and Endocrinology, vol. 6, no. 2, pp. 105-113, 2018.

[52] S. Friberg and S. Mattson, "On the growth rates of human malignant tumors: implications for medical decision making," Journal of Surgical Oncology, vol. 65, no. 4, pp. 284-297, 1997. 


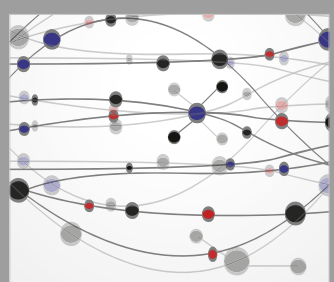

The Scientific World Journal
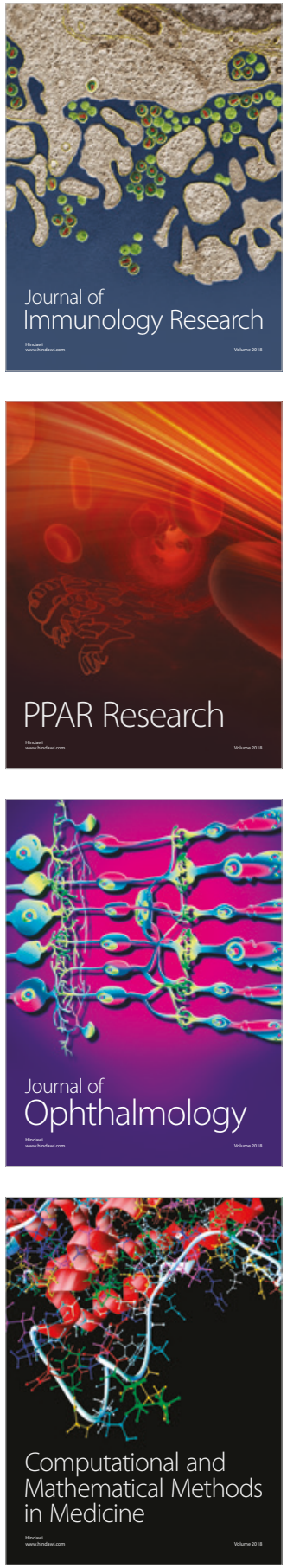

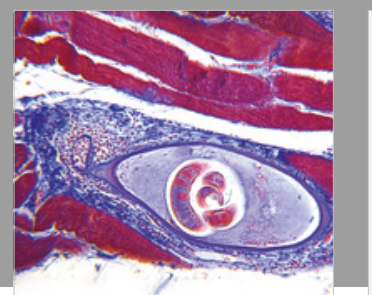

Gastroenterology Research and Practice

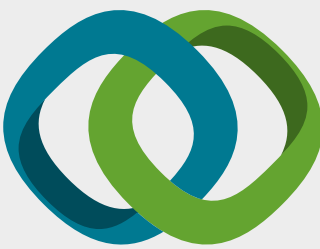

\section{Hindawi}

Submit your manuscripts at

www.hindawi.com
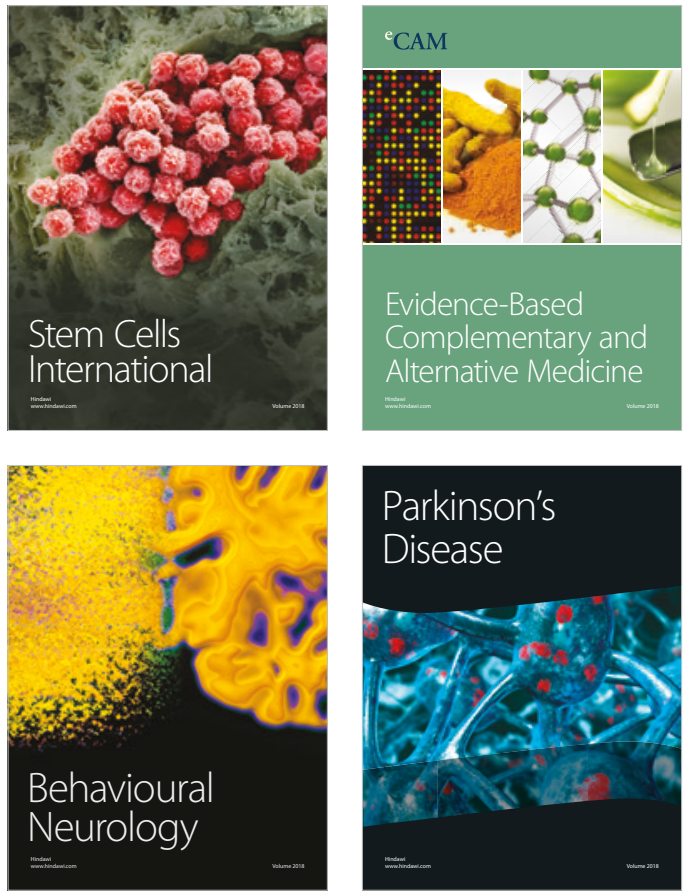

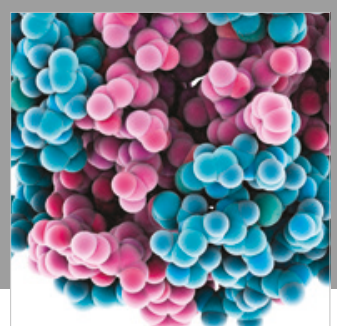

ournal of

Diabetes Research

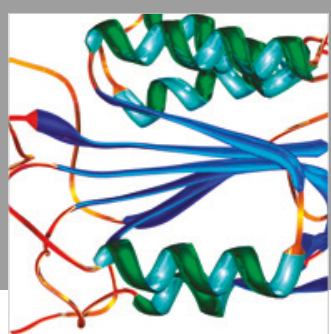

Disease Markers
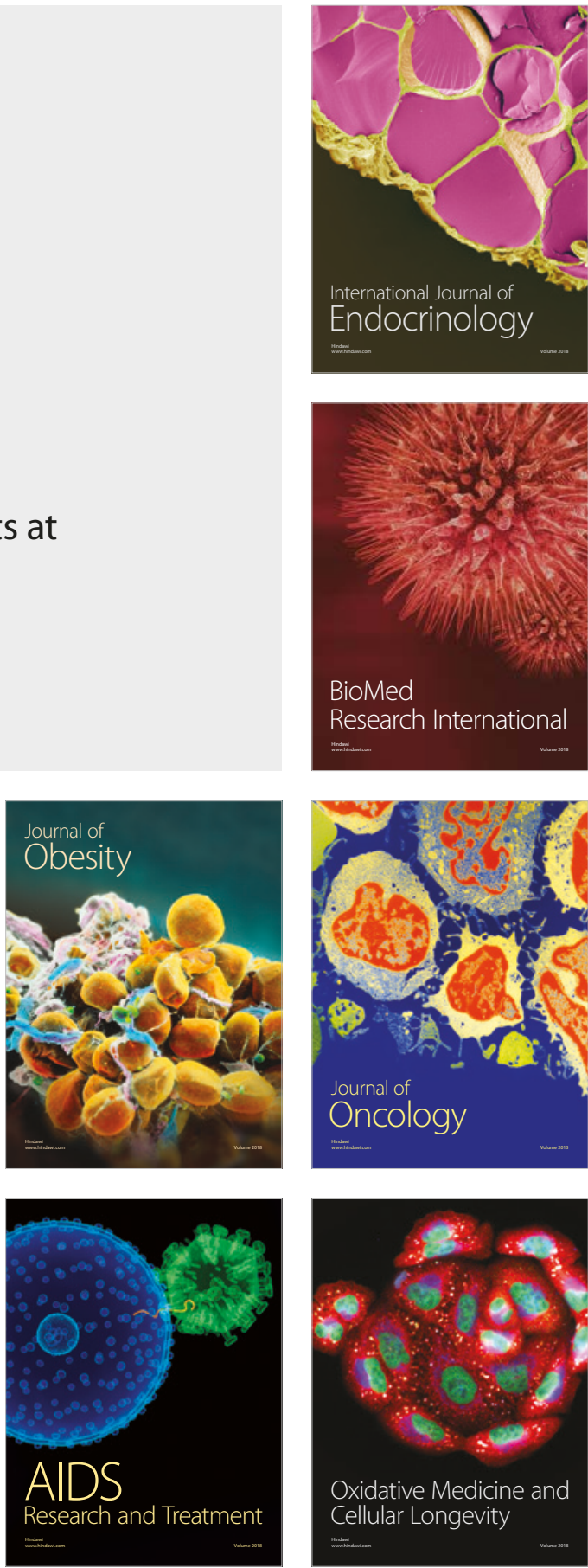